\title{
CONTINUOUS EPIDURAL ANALGESIA: EXPERIENCE WITH MECHANICAL INJECTION DEVICES ${ }^{\circ}$
}

\author{
W. E. SPOEREL, M.D., F.R.C.P. (C), $†$ \\ Ann Thomas, M.D., and G. R. Gerula, M.D.
}

Epidural analgesia can provide pain relief superior to the presently known systemic analgesic drugs in many instances. ${ }^{1,2}$ Psychic and central respiratory depression are avoided and the severly impaired respiration following abdominal and thoracic surgery is restored to near normal levels by the blockade of pain pathways. ${ }^{3}$ Pain caused by pancreatitis, ischaemic conditions of the extremities, and traumatic pain are often better controlled with epidural analgesia ${ }^{2,3}$ and there may be a place for this technique in the management of ischaemic heart disease. ${ }^{3,4}$

One of the problems in maintaining prolonged epidural analgesia is the relatively short duration of action of the presently available local anaesthetic agents. In order to maintain freedom from pain, the epidural analgesia must be reinforced by repeated injections at approximately hourly intervals. The return of pain sensation, after the epidural block has worn off, is rather sudden and severe, and failure to re-inject at the appropriate time leaves the patient with an interval of excruciating pain. ${ }^{5}$

For continuous analgesia the following techniques have been used:

1. Repeated manual injections. These are only satisfactory if medical personnel or nurses are in constant attendance (e.g., in intensive care units, obstetrical suites) and the re-injection can be carried out at the moment the patient experiences pain. For longer cases it requires the use of large syringes which are cumbersome to handle and require great force for injection, or a frequent change of the syringes which is unacceptable because of the difficulty of maintaining sterility.

2. Manual injections in combination with a reservoir. A refilling syringe ${ }^{\boldsymbol{\theta}}$ or a manually operated pump ${ }^{7}$ has been used. Sterility is best maintained with a closed system using a plastic bag. ${ }^{8}$

3. Infusion of local anaesthetic solutions by a continuous drip. Although this technique has been satisfactorily employed, ${ }^{8, \theta}$ the high resistance of the narrow lumen epidural catheter and the possibility of changes in the drop rate due to alteration of the patient's position induce undesirable variables.

4. Injection with the help of mechanical devices. This can be done either by continuous infusion or intermittently by incorporating an electronic timer for repeat injection. ${ }^{5,10}$ With this technique, the volume and dosage of the local anaesthetic agent, as well as the timing of the injection, are rigidly controlled.

'Presented at the Annual Meeting of the Canadian Anaesthetists' Society, Toronto, Ontario, June 16-19, 1969.

†Department of Anaesthesia, University of Western Ontario, London, Canada. 


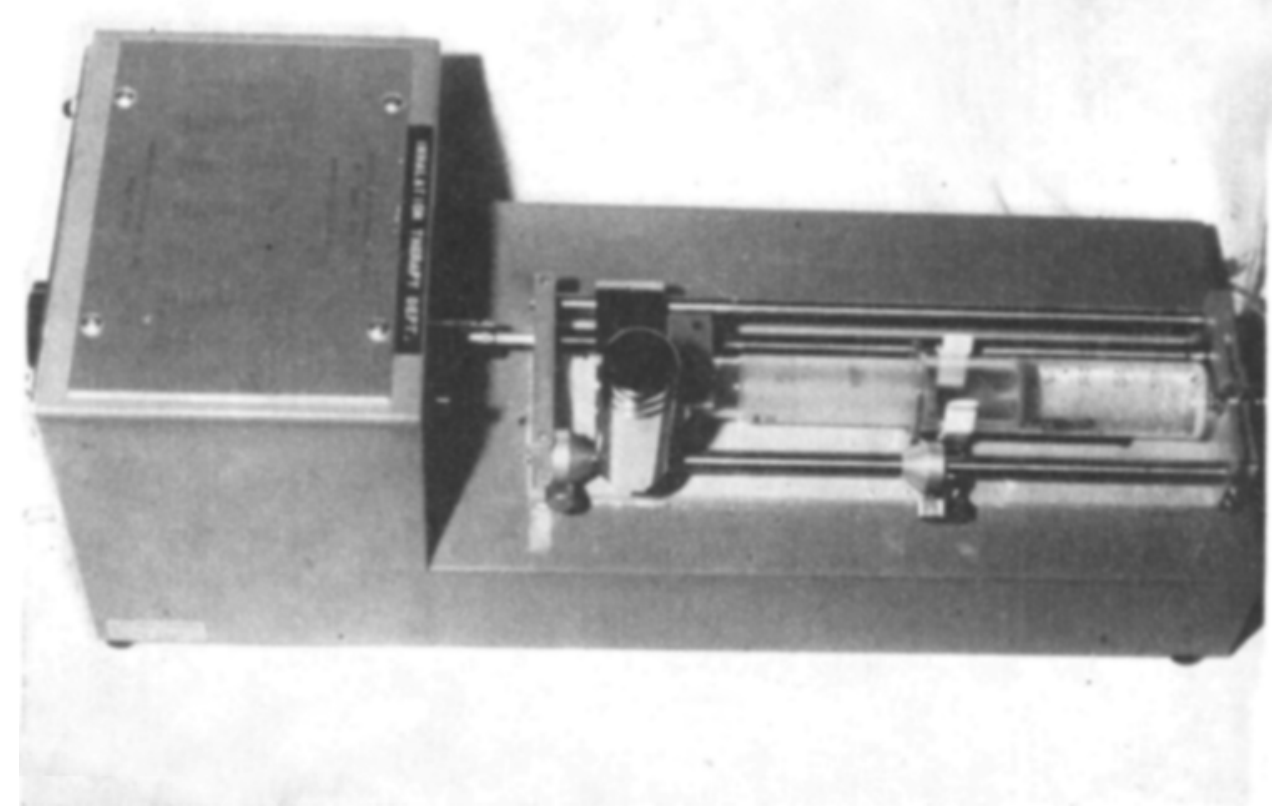

Figure 1. Harvard pump.

Supervision by nurses is necessary, but the nurse does not have to attend the patient at a specific time as she would be required to do with the first two techniques listed.

The use of an electronically timed mechanical injection pump (Harvard Instrument Corporation) for epidural injections was reported in 1963 by Cox and Spoerel. ${ }^{\bar{s}}$ The purpose of this presentation is to report on a wider experience with mechanically injected epidural analgesia and to describe the type of apparatus used for this purpose.

\section{Type of APparatus Used}

\section{A. Continuous Injection Devices}

1. The Harvard pump (Harvard Apparatus Co., Millis, Massachusetts) is a motor-driven syringe, with a gear box providing for different speeds of injection. With the standard-type apparatus and a 50-cc syringe, the injection volumes per hour are approximately 4.8 and $11.6 \mathrm{ml}$ (Fig. 1 ).

2. The Holter pump (The Holter Company, Bridgeport, Pennsylvania) is a rotary pump compressing an elastic plastic tubing. A wide range of injection volumes can be obtained by varying the speed on the rotor or the internal diameter of the tubing. The pump works accurately against a pressure of approximately $300 \mathrm{~mm} \mathrm{Hg}$ (Fig. 2)

\section{B. Intermittent Injection Devices}

1. A modified Harvard pump, providing an injection volume of $1.27 \mathrm{ml}$ per minute with a $50 \mathrm{cc}$ syringe, was attached to a timing device which sets the 


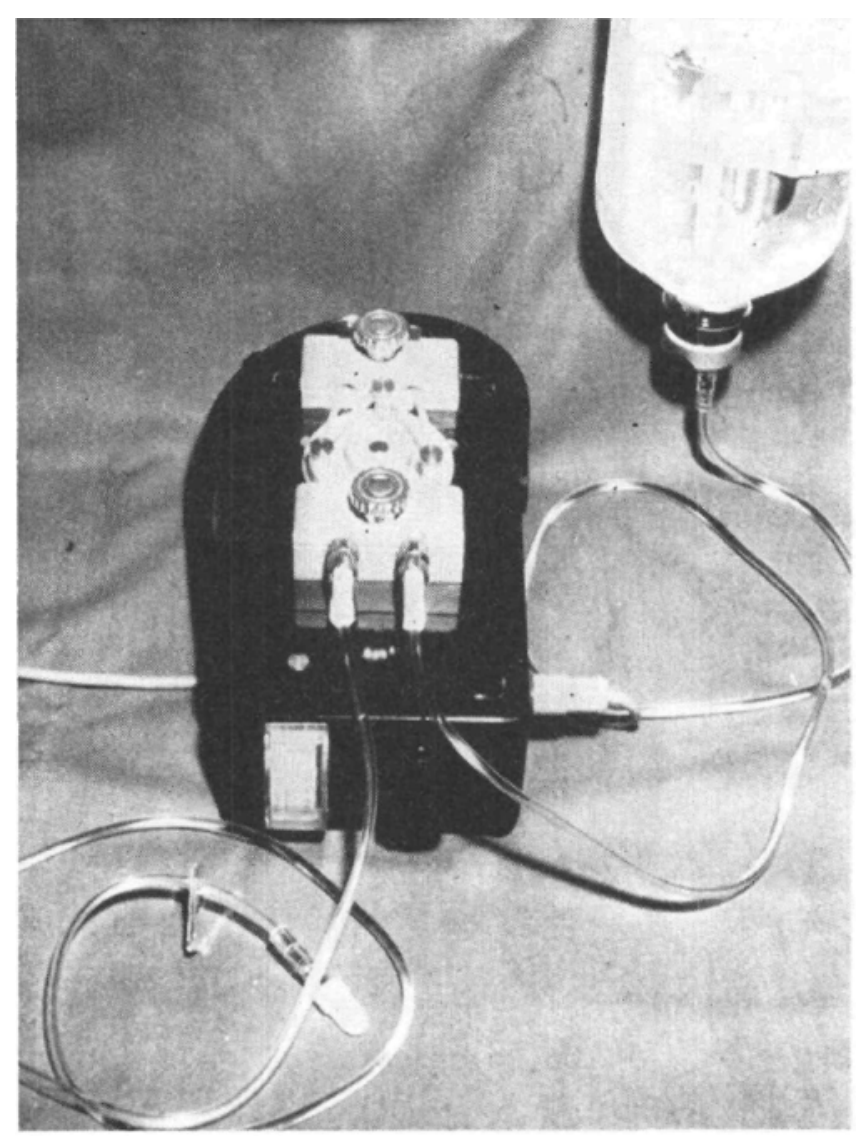

Figune 2. Holter pump.

syringe in motion for a specified number of minutes. The volume of fluid discharged from the syringe is 1.27 times the number of minutes for which this timer is set. This injection sequence is controlled by a second timer allowing the sequence to occur at multiples of 15 minutes (Fig. 3).

2. A regular Harvard pump was attached to a fixed timing device so that the combination would allow the hourly injection of $7 \mathrm{ml}$. This combination was mainly used for epidural analgesia in obstetrics.

3. A mechanism was constructed for the automatic injection and refilling of a $10 \mathrm{ml}$. syringe at variable intervals ranging from 3 to 100 minutes (Fig. 4). The syringe is discharged by a spring mechanism exerting 50 pounds of pressure (Fig. 5). The syringe is attached to a Y-piece and disposable plastic tubing, one bringing fluid from a reservoir to the syringe, the other carrying it to the patient. During the injection phase the tubing to the reservoir is occluded by an electromagnetic clamp. "When the syringe has discharged completely, a switch is triggered starting an electric motor which pulls the plunger back into its original

"A disposable pressure infusion set incorporating two one-way valves has recently been introduced by Travenol Laboratories Inc. This set works satisfactorily with an automatic refilling syringe, obviating the need for the electromagnetic clamp. 


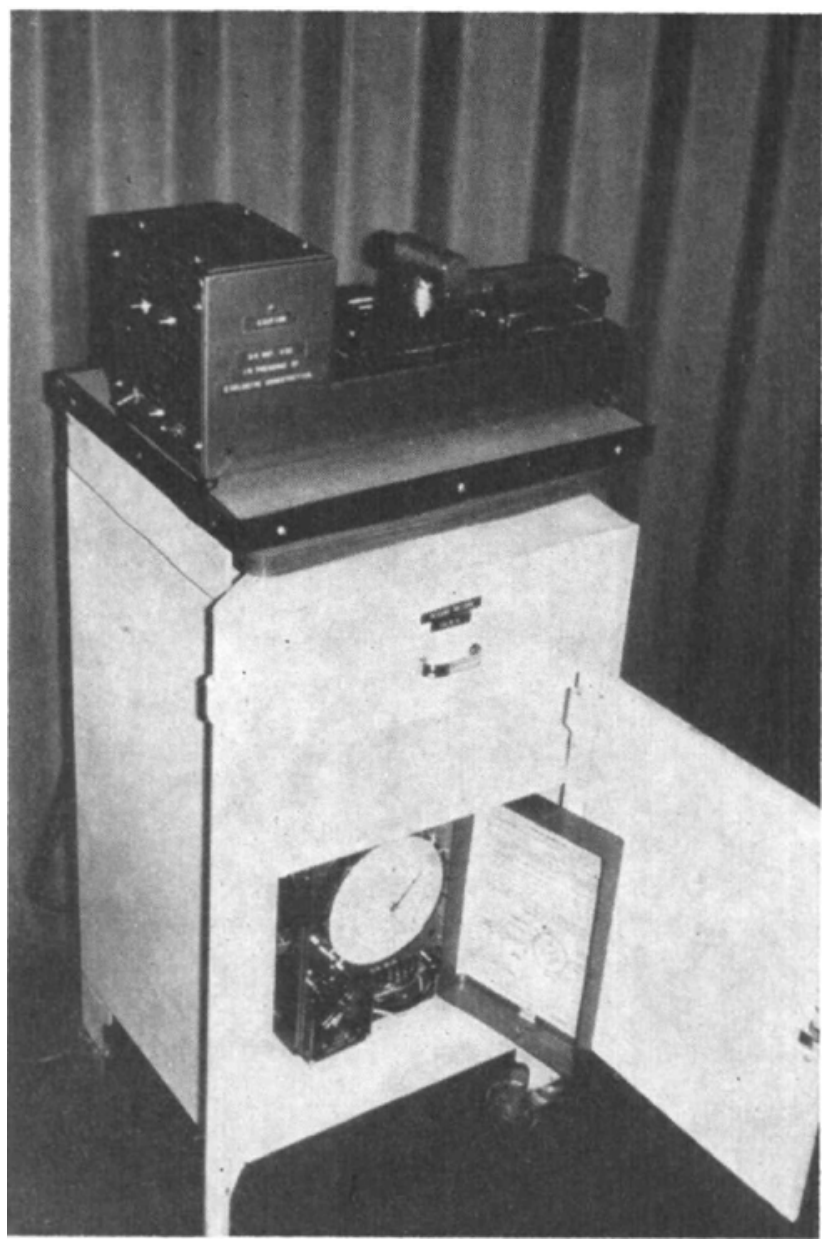

Figure 3. Harvard pump with double timer.

position and simultaneously reloads the spring mechanism. Spring and motor are mounted on a movable panel, and, by turning a screw, the distance of this panel to the syringe can be altered while the plunger of the syringe follows the panel; in this way the flling of the syringe can be changed. Once the mechanism is set, the syringe will always refill with the same volume of fluid. The discharge mechanism is controlled by a timer but can also be initiated manually.

\section{Management of Patients}

Continuous epidural analgesia using a mechanical injection device was started in all patients in the recovery room or intensive care unit. Some patients with stable conditions were allowed to return to the ward after two or three days while the epidural analgesia continued. The mechanism was set up by the anaesthetist or the resident in anaesthesia, and all necessary adjustments and maintenance operations were done by them. The nurses were given instructions as to 


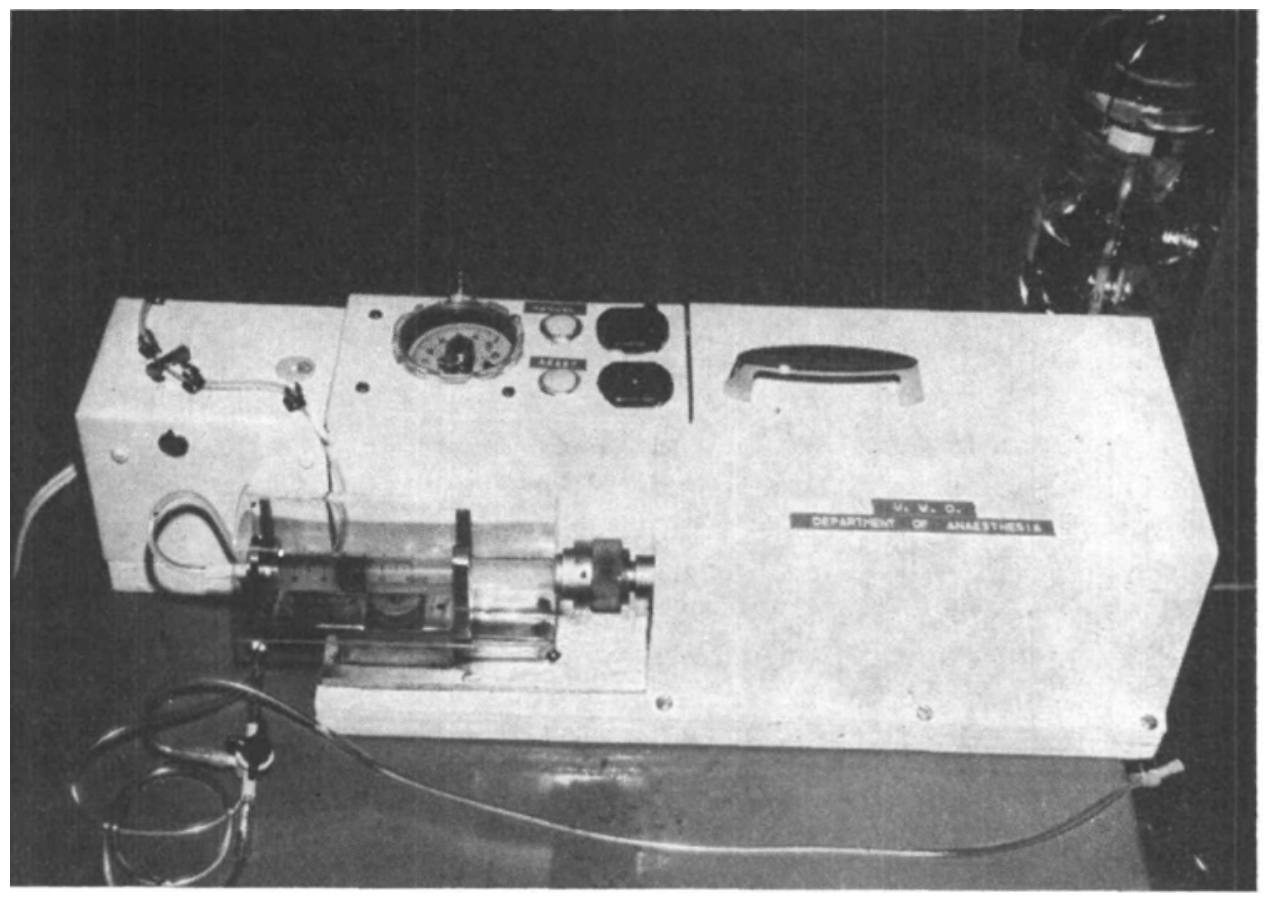

Figure 4. Injection apparatus with automatically refilling syringe.

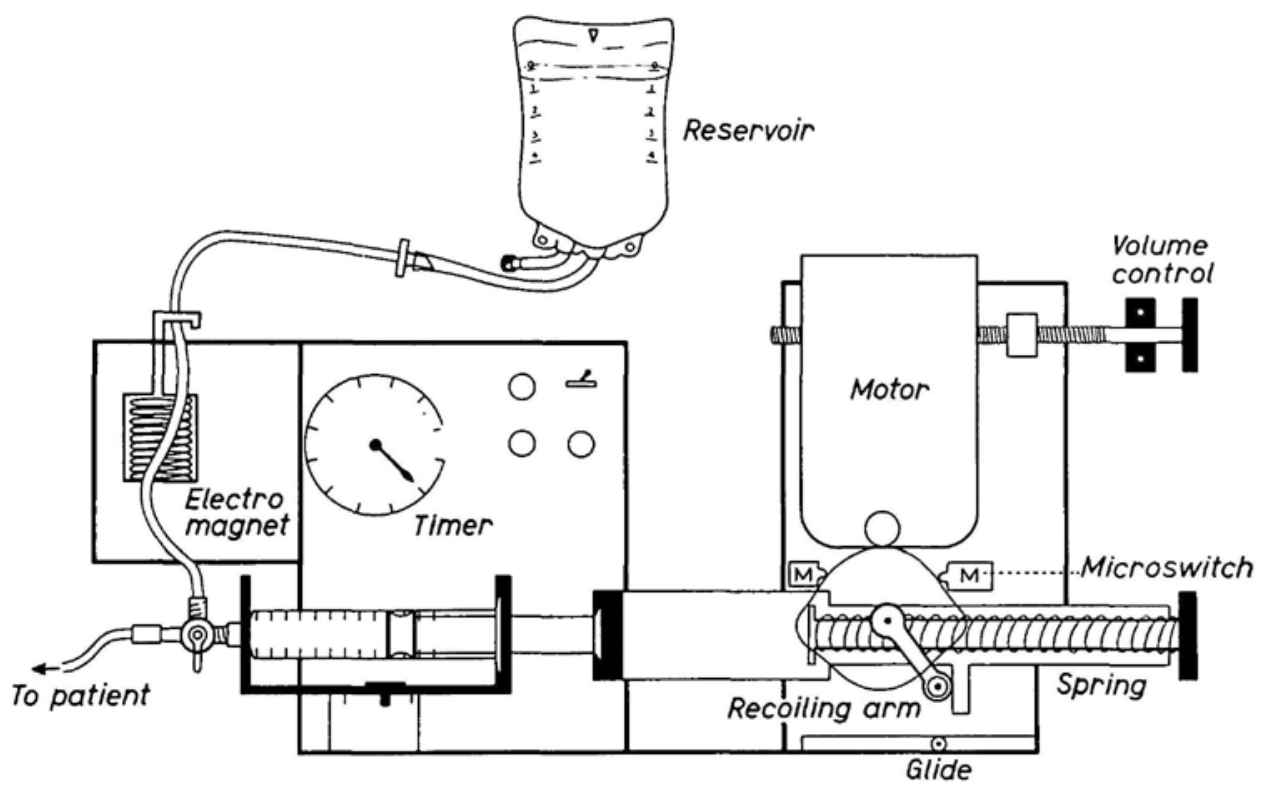

Automatic intermittent injection device

FIGURE 5. Schematic drawing of apparatus with automatically reflling syringe (description in text). 
the function of the apparatus and asked to disconnect at the electrical outlet if the apparatus was not functioning properly or if the patient showed signs of extensive anaesthesia, hypotension, or any other untoward symptoms. In these instances, the anaesthetist on call was summoned immediately. The anaesthesia resident also was responsible for the refilling of the syringes on the Harvard pump or for changing the solution containers in the others, and was informed when the patient did not have adequate pain relief.

\section{REsults}

A review was made of 135 patients in whom mechanically injected epidural analgesia was used for the relief of postoperative and other forms of pain. In addition 68 obstetrical patients with mechanically injected epidural analgesia were considered.

Long-term continuous epidural analgesia was most frequently used following major abdominal surgery, and also for surgery on the abdominal aorta or the arterial system of the lower extremities (Table I). The remainder were pain problems including such conditions as chest trauma, pancreatitis, pain due to malignancy, and other forms of chronic pain. One patient received four longterm epidurals for intractable diarrhoea of unexplained origin. On each occasion the epidural was followed by a remission of several months.

In 102 patients, or 76 per cent, the epidural analgesia provided adequate pain relief and the patient did not require more than $100 \mathrm{mg}$. of demerol or an equivalent dose of other systemic analgesics per day (Table II). In 26 patients, or 19 per cent, the result was considered fair, indicating that the patient was not at times adequately relieved and required a daily dose of systemic analgesia in excess of $100 \mathrm{mg}$ demerol. However, the epidural analgesia contributed signifcantly to the total comfort of the patient in all cases. In 7 cases, or 5 per cent, the result was considered poor, usually due to technical problems with the epidural catheter, the apparatus, or the early development of tachyphylaxis. An intermittent injection device was used in 70 per cent of these patients throughout the whole course, and a continuous injection device in 22 per cent. In 8 per cent

TABLE I

Case Classification and Duration

\begin{tabular}{lccc}
\hline \hline \multicolumn{1}{c}{ Indication } & $\begin{array}{c}\text { Number of } \\
\text { cases }\end{array}$ & $\begin{array}{c}\text { Range in } \\
\text { hours }\end{array}$ & $\begin{array}{c}\text { Average number } \\
\text { of hours }\end{array}$ \\
\hline Abdominal surgery & 38 & $12-104$ & 49 \\
Abdoninal perineal resection & 2 & $3-51$ & 27 \\
Pelvic and perineal surgery & 3 & $30-52$ & 43 \\
Ileal loop and/or cystectomy & 24 & $8-140$ & 75 \\
Surgery - abdominal aorta & 8 & $6-87$ & 54 \\
Peripheral vascular problems & 20 & $12-201$ & 82 \\
Radical hysterectomy & 8 & $3-83$ & 43 \\
Pancreas pathology & 12 & $11-312$ & 106 \\
Chest trauma & 7 & $48-168$ & 81 \\
Chronic pain & 9 & $27-329$ & 104 \\
Miscellaneous & 4 & $30-195$ & 107 \\
Total cases & 135 & & 70 \\
\hline
\end{tabular}


TABLE II

Injection Techniques and Results

\begin{tabular}{lrccr}
\hline \hline \multirow{2}{*}{ Method } & \multicolumn{4}{c}{ Results (number of patients) } \\
\cline { 2 - 5 } & good & fair & poor & total \\
\hline Mechanical intermittent & 73 & 16 & 6 & 95 \\
Mechanical continuous & 24 & 7 & 0 & 31 \\
Mechanical and manual & 5 & 3 & 1 & 9 \\
& & & & 135 \\
\hline
\end{tabular}

TABLE III

Local. Anaesthetic Agents Used (Number of Cases)

\begin{tabular}{lcc}
\hline & Plain solution & With adrenaline \\
\hline Xylocaine & & \\
$0.5 \%$ & 0 & 15 \\
$1.0 \%$ & 18 & 1 \\
$1.5 \%$ & 31 & 26 \\
$2.0 \%$ & 9 & 8 \\
Carbocaine & 10 & 0 \\
$1.0 \%$ & 8 & 0 \\
$1.5 \%$ & 1 & 0 \\
$2.0 \%$ & 8 & 0 \\
Others or unknown & & \\
\hline
\end{tabular}

the injection was carried out manually during a significant part of the period of analgesia.

The local anaesthetic solutions initially used were Xylocaine ${ }^{\circledR}$ in various concentrations without adrenaline in 43 per cent, with adrenaline in 37 per cent, and with Carbocaine ${ }^{\circledR}$ in 14 per cent of cases (Table III). The dosage of local anaesthetic agents in milligrams and the site of introduction of the epidural catheter are shown in Figures 6 to 9. For abdominal surgery the catheter was introduced between L $3 / 4$ and T $9 / 10$ (Fig. 6 ). The results classified as fair appeared to be randomly distributed over the dosage range and with the exception of the lowest dosage are probably not related to this factor. For patients recovering from ileal loop conduit and cystectomy (Fig. 7) the incidence of only fair results was higher, probably due to the wide area of analgesia required for complete pain relief. For peripheral vascular surgery (Fig. 8) the catheter had been introduced in the lumbar region; the dosage may have been too low for three patients, producing only fair results. The single poor result was likely due to faulty position of the catheter. In the patients with pancreatic pain (Fig. 9) the epidural puncture was done between T 8 and T 12 with one exception, and the one fair result was at the lower dosage range.

\section{COMPLiCATIONS}

In 18 patients the analgesia was incomplete (Table IV); there was often an unilateral deficiency of analgesia and this could be due to the position of the catheter. ${ }^{11}$ Significant hypotension was encountered in only 17 cases and could 


\section{Abdominal surgery}

Number of patients, 36

Average duration of Analgesia, 49 hours

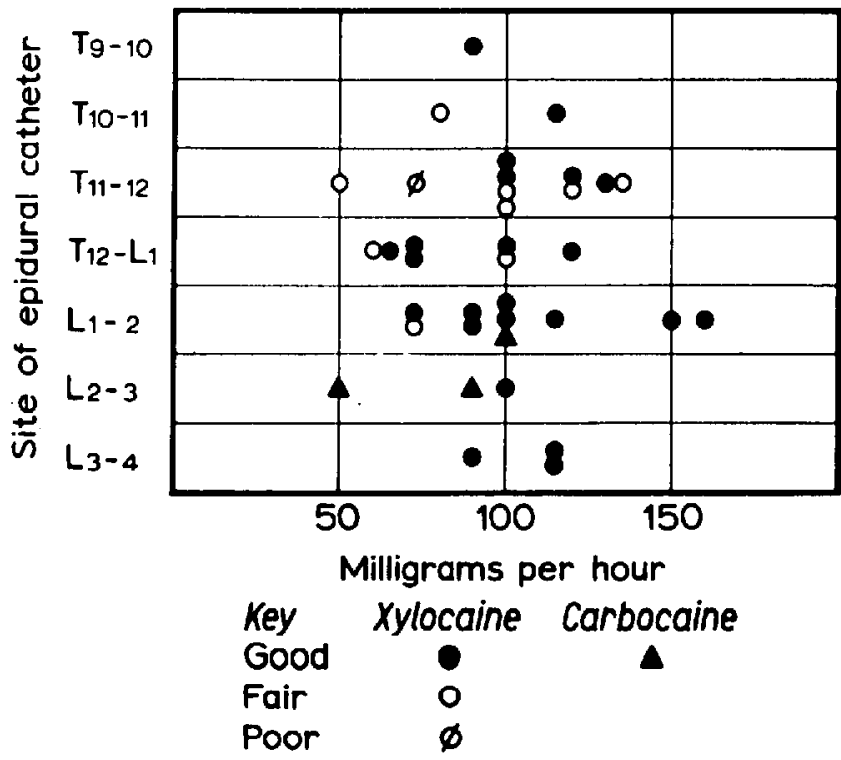

Figure 6. Postoperative continuous epidural analgesia: site of catheter, hourly dosage of local anaesthetic agent, and assessment of analgesia.

\section{Ileal loop $+/$ - cystectomy}

Number of patients, 20

Average duration of Analgesia, 75 hours
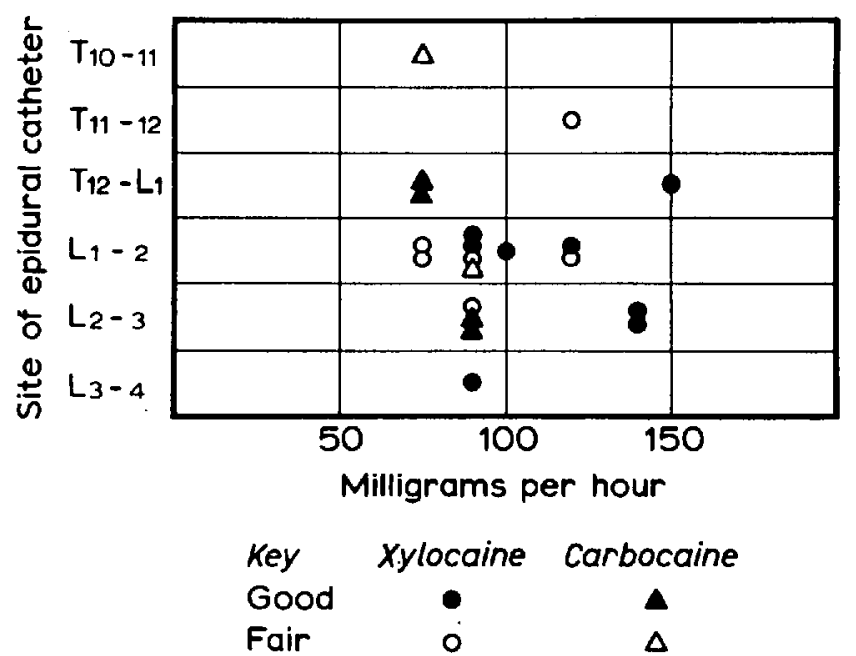

Figure 7. Postoperative continuous epidural analgesia: site of catheter, hourly dosage of local anaesthetic agent, and assessment of analgesia. 
SPOEREL et al.: CONTINUOUS EPIDURAL ANALGESLA

\section{Peripheral vascular problems}

Number of patients, 14
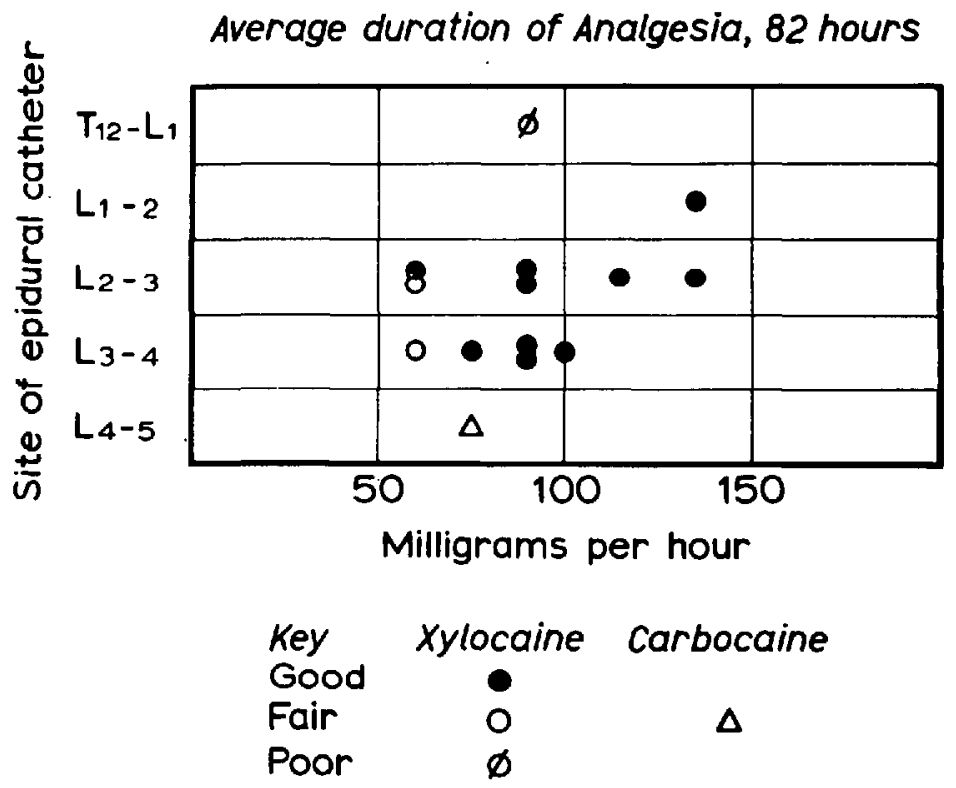

FIGURE 8. Continuous epidural analgesia: site of catheter, hourly dosage of local anaesthetic agent, and assessment of analgesia.

\section{Pancreas pathology}

Number of patients, 11 Average duration of Analgesia, 106 hours
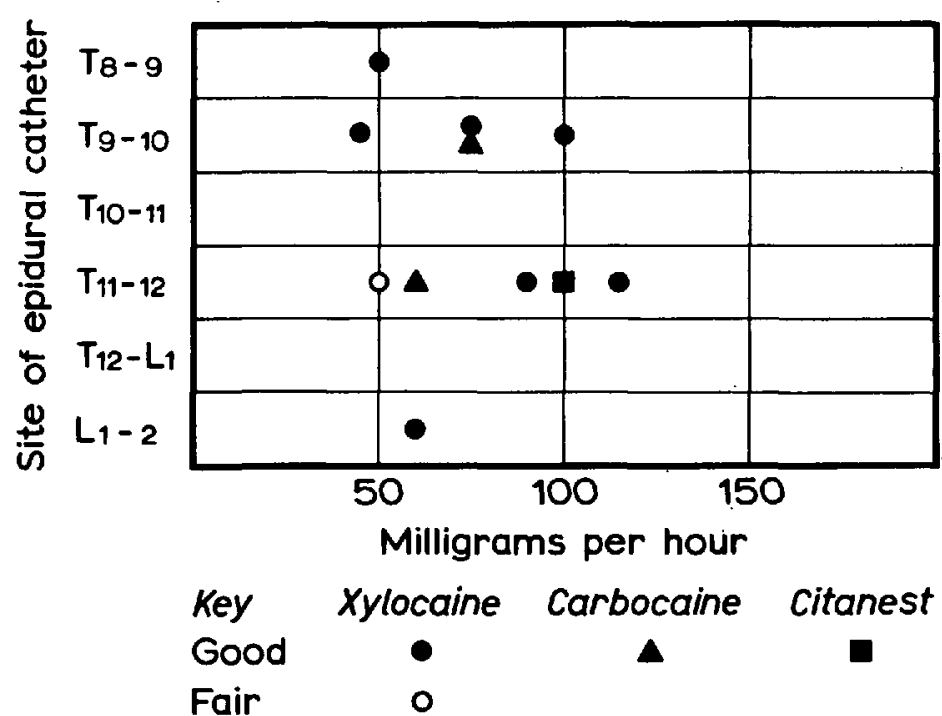

FIgUre 9. Continuous epidural analgesia: site of catheter, hourly dosage of local anaesthetic agent, and assessment of analgesia. 
TABLE IV

COMplications in 135 Cases

\begin{tabular}{lr}
\hline \hline Incomplete analgesia & 18 \\
Hypotension & 17 \\
Catheter problem & 12 \\
Apparatus problem & 11 \\
Meningeal irritation & 14 \\
Excess spread & 2 \\
Toxicity & 1 \\
Tachyphylaxis & 40 \\
\hline
\end{tabular}

usually be corrected by a small dose of vasopressor and an increase in intravenous infusion; no continuous vasopressor infusion was employed. Technical problems with the catheter consisted of leakage or blockage, or occurred when the catheter had slipped out of the epidural space or became disconnected. Sticky syringes were the most frequent apparatus problem apart from initial troubles with new modifications.

The 14 patients listed under meningeal irritation include all those who exhibited any pain referred to the spine. Pain about the catheter site presented a peculiar cycle, i.e., the patients complained of a localized back pain about the catheter site, and the epidural analgesia was continued to treat this pain. In all cases the pain subsided within a few hours after removal of the epidural catheter. Signs of more widespread meningeal irritation, e.g., stiffness of the neck, ${ }^{5}$ have not been seen in recent years, probably due to better attention to technique.

Excessive spread of the analgesia, causing numbness of arms and hands, occurred in two patients. Systemic toxicity was observed only once in an elderly patient who received approximately $200 \mathrm{mg}$ of Xylocaine per hour in an attempt to maintain complete analgesia. He became increasingly obtunded and finally unconscious. Responsiveness returned within two to three hours after the injections were discontinued.

\section{TACHYPHYLAXIS}

A decrease in duration, intensity, and extent of the effect of the local anaesthetic agents used was one of the main problems in maintaining satisfactory epidural analgesia. ${ }^{1,3,5,12}$ If the duration of analgesia decreased below one hour, a painful interval developed between the end of analgesia and the timed hourly injection. In 26 patients ( Table V), records were sufficient to determine the onset

TABLE $\mathrm{V}$

Mechanical Intermitent Injections: Onset of Interval Pain in 26 Patients

\begin{tabular}{ccccccc}
\hline $\begin{array}{c}\text { Hours after start of } \\
\text { timed intermittent } \\
\text { injections }\end{array}$ & $\begin{array}{c}\text { Xylocaine } \\
(1 \%)\end{array}$ & $\begin{array}{c}\text { Xylocaine } \\
(\mathbf{1 . 5 \% )}\end{array}$ & $\begin{array}{c}\text { Xylocaine } \\
(2 \%)\end{array}$ & $\begin{array}{c}\text { Xylocaine } \\
(\mathbf{1 . 5 \% )} \\
\text { +adrenaline }\end{array}$ & $\begin{array}{c}\text { Carbocaine } \\
(\mathbf{1} \%)\end{array}$ & Totals \\
\hline$<6$ & 2 & - & - & - & 1 & 3 \\
$6-12$ & 1 & 3 & - & - & 2 & 6 \\
$12-24$ & 2 & 1 & 1 & 1 & 2 & 8 \\
$24-36$ & 2 & 1 & 2 & - & & 1 \\
$>36$ & - & 1 & - & & & 26
\end{tabular}


TABLE VI

Obstetrical Cases with Continuous or Intermittent Mechanical Injections: Additional Injections Required and Duration of Analgesia

\begin{tabular}{lccccc}
\hline \hline & \multicolumn{2}{c}{ Continuous infusion } & & \multicolumn{2}{c}{ Intermittent injections } \\
\cline { 2 - 3 } & cases & average duration (min) & cases & average duration (min) \\
\hline $\begin{array}{l}\text { No additional injections } \\
\text { One additional injection at }\end{array}$ & 26 & 250 & 18 & 410 \\
$\begin{array}{l}\text { end of first stage } \\
\text { Two or more additional } \\
\text { injections }\end{array}$ & 11 & 400 & 1 & 250 \\
& $\frac{11}{48}$ & 550 & 1 & 1020 \\
\hline
\end{tabular}

of this interval pain. Although there are considerable individual variations, the distribution suggests that this phenomenon is likely to occur earlier with weaker solutions. In most patients a change to a higher concentration or the addition of adrenaline re-established satisfactory analgesia for some time; occasionally the procedure had to be abandoned. Cohen et al. ${ }^{13}$ presented evidence that this tachyphylaxis may be associated with changes in $\mathrm{pH}$ and shifts in the amounts in ionized and non-ionized forms of local anaesthetics.

\section{CONTINUOUS OR INTERMITTENT InJections}

In order to assess the Holter pump as a means of providing accurate continuous infusion, 68 obstetrical patients with continuous epidural analgesia were studied. Xylocaine 1.5 per cent with $1: 200,000$ adrenaline was infused at a rate of 6 to $8 \mathrm{ml}$ per hour in 48 patients; 20 received the same dosage given with an intermittent injection device every hour. The epidural catheters were placed at $\mathrm{L} 2$ and 3 in 60 per cent of the cases and at $\mathrm{L} 3$ and 4 in the remainder. In both groups intermittent manual injections of the same volume were given in addition, whenever the analgesia became inadequate. A terminal manual injection was made in preparation for the delivery.

With an intermittent injection device, 18 of the 20 patients maintained satisfactory analgesia (Table VI) for an average of 410 minutes. One patient received an additional injection when the cervix was nearly fully dilated. Three additional injections were given to a patient where epidural analgesia was maintained for 17 hours.

With continuous infusion, 26 out of 48 had satisfactory analgesia without additional injections. One injection was required near the beginning of the second stage in 11 patients and the other 11 required two or more additional injections. It should be noted that the need for additional injections increased with the duration of analgesia.

\section{Epidural Analgesia with Weak Solutions}

It has been suggested that a safer and more consistent analgesia could be obtained by using .5 per cent Xylocaine with adrenaline. ${ }^{14}$ This technique was used 
in 15 cases following major abdominal surgery with epidural catheters placed in the region of $\mathrm{T} 11$ to $\mathrm{L} 2$. Two per cent Xylocaine with 1:100,000 adrenaline was diluted with saline to make a .5 per cent solution. Injections were given intermittently in six patients and continuously in nine. The results were rather varied, and further experience is required in order to use this technique satisfactorily. The dosage per hour required to obtain adequate pain relief appears to be of the same order as in cases where more concentrated solutions had been used (Fig. 10).

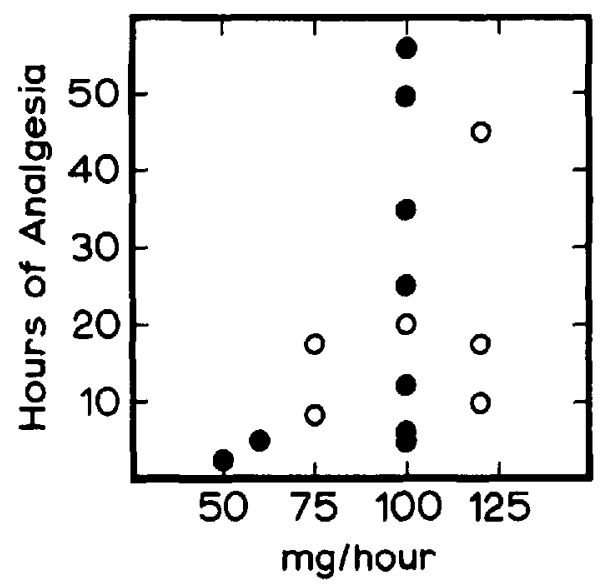

FIgure 10. Continuous epidural analgesia using 0.5 per cent xylocaine $+1: 400,000$ adrenaline by continuous infusion (O) or intermittent injections at 20 minute intervals (•) for pain relief after major abdominal surgery (15 patients). Hourly dosage of xylocaine in $\mathrm{mg}$. Epidural catheter introduced between $\mathrm{T} 11$ and $L$ 2. Duration of satisfactory analgesia in hours.

\section{Conclusion}

In our opinion mechanical injection devices are useful and safe for the maintenance of continuous epidural analgesia. For their satisfactory employment, good technical maintenance of the apparatus and acquaintance of the nurses with its use are essential. In our Institution this has become a routine technique with long-term epidural analgesia, and nurses as well as patients have accepted it. The hourly starting of the intermittent devices is occasionally disturbing to patients.

The use of long-term continuous epidural analgesia requires a great deal of attention to detail regarding the placement of the catheter and connections, as well as attention to the apparatus. Satisfactory results can only be obtained where a 24-hour coverage is possible with anaesthetists and residents who are thoroughly familiar with epidural analgesia.

Apart from technical problems, tachyphylaxis, or the decay of analgesia, ${ }^{12}$ is the main problem. Particularly with automatic intermittent injections, a rigid 
schedule is imposed which breaks down once the duration of analgesia becomes less than the injection intervals. The resurgence of pain and the anxious awaiting of the relief-bringing injection can be very aggravating to patients. An increase in the dosage of the local anaesthetic agent or the addition of adrenaline only partially solves this problem.

Patient acceptance was at times difficult to assess. Initially a proper epidural block always provided excellent pain relief and patients were quite content. With time, however, many patients became somewhat disturbed and anxious and began to complain about some degree of discomfort in spite of an apparently adequate extent of skin analgesia. Small doses of an opiate analgesic, e.g. Demerol 25-50 mg, were often helpful under these circumstances. On occasion we felt that the epidural block was no longer contributing significantly to the patient's comfort and discontinued the epidural injections; the usual regimen with systemic analgesics was then used. On several such occasions we restarted the epidural analgesia at the patients' request a few hours later.

\section{Summary}

Continuous epidural analgesia requires repeated injections or the continuous infusion of local anaesthetic solutions. Two commercially available infusion pumps have been used for continuous infusions and one of these was equipped with an electronic timing device for intermittent injections. An automatic refilling syringe of our own design was also used and is described in detail.

The results of long-term continuous epidural analgesia with mechanical injection devices in 135 patients are reviewed. In 76 per cent of these, completely satisfactory analgesia could be maintained in postoperative patients and other pain problems, e.g. pancreatitis, arterial insufficiency of the lower extremities, chest trauma, and malignancy. The complications encountered are discussed; the main problem was a tachyphylaxis to the local anaesthetic agents, i.e., a decrease in duration and intensity of the epidural block.

A technique using a 0.5 per cent Xylocaine with $1: 400,000$ adrenaline was employed in 15 of the postsurgical patients; the pain relief was less consistent when compared with the use of higher concentrations of the same agent while the total dosages required were similar.

In an additional 68 obstetrical patients the maintenance of the epidural block with intermittent injections proved more satisfactory than with a continuous infusion.

In our experience, mechanical injection devices provide a satisfactory means for the maintenance of continuous epidural analgesia.

\section{RÉSUMÉ}

L’analgésie épidurale continue demande des injections répétées ou l'infusion continue de solutions d'anesthésique local. On a utilisé deux pompes à infusions actuellement sur le marché pour des infusions continues, et l'une d'elles était munie d'un dispositif de réglage électronique pour injections intermittentes. On 
s'est servi aussi d'une seringue à remplissage automatique de notre fabrication et on la décrit en détail.

On passe en revue les résultats d'épidurale continue prolongée à l'aide d'appareils à injection mécanique chez 135 malades. Pour 76 pour cent de ces derniers, on a pu maintenir une analgésie tout à fait satisfaisante dans les suites post-opératoires et pour d'autres problèmes de douleurs, tels que pancréatite, insuffisance artérielle des membres inférieurs, traumatismes thoraciques et tumeurs malignes. On analyse les complications observées; le problème principal fut une tachyphylaxie aux agents anesthésiques locaux, c'est-à-dire une diminution dans la durée et l'intensité du bloc épidural.

On a utilisé une technique comme suit: 0.5 pour cent de Xylocaine additionnée d'adrénaline à 1 pour 400,000 chez 15 des malades qui venaient de subir une opération; le soulagement de la douleur était moindre que si l'on utilisait de plus fortes concentrations du même agent, alors que les doses totales requises étaient les mêmes.

Dans un autre groupe de 68 parturientes, le maintien du bloc épidural à l'aide d'injections intermittentes s'est avéré plus satisfaisant qu'a l'aide d'une infusion continue.

D'après notre expérience, les dispositifs d'injection mécanique fournissent un moyen satisfaisant pour maintenir une analgésie épidurale continue.

\section{ACKNOWLEDGMENTS}

The automatic refilling syringe was designed and manufactured by $\mathrm{Mr}$. $\mathrm{H}$. Berger. Various modifications of the apparatus used were carried out by $\mathrm{Mr}$. Grauds, R.I.T.T, and electricians of the Maintenance Staff, Victoria Hospital, London, Ontario. We also wish to thank the members of the Department of Anaesthesia, Victoria Hospital, for their interest and co-operation, and Mr. T. Walco for technical assistance at Westminster Hospital.

\section{REFERENCES}

1. Bhomace, P. R. Physiology and Pharmacology of Epidural Analgesia. Anesthesiology. 28: 592 (1967).

2. Lund, P. C. Peridural Analgesia and Anaesthesia. Springfield, Ill.: Charles C Thomas (1966).

3. Bromage, P. R. Extradural Analgesia for Pain Relief. Brit. J. Anaesth. 39: 721 (1967).

4. Skelton, R. B.; Gergely, N.; Manning, G. W.; \& Coles, J. C. Mortality Studies in Experimental Coronary Occlusion. J. Thorac. and Cardiov. Surg. 44: 90 (1962),

5. Cox, J. M. R. \& Spoerel, W. E. Continuous Epidural Analgesia: The Use of an Intermittent Injection Device. Canad. Anaesth. Soc. J. 11: 72 (1964).

6. Atherlex, D. W. An Apparatus for Continuous Epidural Analgesia. Anaesthesia. 16: $503(1961)$.

7. Scott, D. B. \& Walker, L. R. Administration of Continuous Epidural Analgesia. Anaesthesia, 18: 82 (1963).

8. Burn, J. M. B. A Method of Continuous Epidural Analgesia. Anaesthesia. I8: 78 (1963).

9. Massey-Dawnins, C. J. Relief of Postoperative Pain by Continuous Epidural Drip. Quoted from Survey of Anesthesiology. 1:616 (1957).

10. Ditzler, J. W. Personal communication. 
11. Bridenbauch, L. D.; Moofe, D. C.; Badgi, P.; \& Brmenbaugh, P. O. The Position of Plastic Tubing in Continuous Block Techniques: An X-ray Study of 552 Patients. Anesthesiology. 29: 1047 (1968).

12. Bromage, P. R.; Pertigrew, R. T.; \& Crowell, D. E. Tachyphylaxis in Epidural Analgesia. 1. Augmentation and Decay of Local Anaesthesia. J. of Clin. Pharmacol. 9: 30 (1969).

13. Cormen, E. N.; Levine, D. A.; Collis, J. E.; \& Gunther, R. E. The Role of pH in the Development of Tachyphylaxis to Local Anaesthetic Agents. Anaesthesiology. 29: 994 (1968).

14. Green, R. \& Massey-Dawkins, C. J. Postoperative Analgesia: The Use of Continuous Drip Epidural Block. Anaesthesia. 21: 372 (1968). 